\title{
A Sociolinguistic Study of the Use of Refusal Strategies by Saudi and American Females
}

\author{
Naimah Ahmad S. Al-Ghamdi ${ }^{1} \&$ Ibrahim R. Alqarni ${ }^{2}$ \\ ${ }^{1}$ Department of English, College of Arts, Imam Abdulrahman Bin Faisal University, Saudi Arabia \\ ${ }^{2}$ Department of English and Translation, King Saud University, Riyadh, Saudi Arabia \\ Correspondence: Naimah Ahmad S. Al-Ghamdi, Assistant Professor of Applied Linguistics, Department of \\ English, College of Arts, Imam Abdulrahman Bin Faisal University, P.O. Box 1982, Dammam, Saudi Arabia. \\ E-mail: dr.naimah666@gmail.com
}

Received: July 11, 2019 Accepted: August 10, 2019 Online Published: August 26, 2019

doi:10.5539/ijel.v9n5p66 URL: https://doi.org/10.5539/ijel.v9n5p66

\begin{abstract}
This paper examines refusal strategies employed in invitations and requests used by Saudi and American female students. As speakers' performances in refusals vary, the paper investigates the content of the semantic formulas and their frequencies in the speech acts of these females when interacting with different interlocutors of different statuses. The assumption proposed in this paper is that speech acts reflect the cultural norms and values of speakers from different cultures (e.g., Arabs' collectivist culture vs American individualistic culture). The analysis and description of refusal strategies are motivated by the need to provide new information on how native speakers really use language, rather than how we think they perform such acts. Data collected in this paper is based on speech acts of refusals employed by a sample of Saudi and American female students.
\end{abstract}

Keywords: refusal strategies, speech acts, speech community, socio-cultural values

\section{Introduction}

Introduction in the literature, there are many attempts to explore how different speech acts are performed across languages and how these performances underpin different norms and values of societies (e.g., Wolfson, 1981; Blum-Kulka \& House, 1989; Olshtain, 1989; Wolfson, Marmor, \& Jones, 1989; Beebe, Takahashi, \& Uliss-Weltz, 1990; Almansoob, Patil, \& Alrefaee, 2019). Refusal strategies may serve as an illuminating source of information on the socio-cultural values of a speech community, and provide important insights into the social norms that are embedded in different cultures. Speech acts of refusal, in general, are minimal and functional units of discourse communication (Searle, 1969; Cohen, 1995, as cited in Nelson et al., 2002) and they often necessitate indirect strategies (Brown \& Levinson, 1978). That is why they are selected to be the data of this study. They are considered as "one of the central issues of intercultural communication" (Phuong, 2006); this is because of the various functions they perform in discourse.

According to Beebe et al. (1990), refusals are a major "sticking point" for nonnative speakers and are complex in nature. Yamagashira (2001) described the speech acts of refusals as a "sensitive pragmatic task" simply because interlocutors, in performing refusals, use indirect strategies in order not to offend each other. In doing so, as Yamagashira (2001) argued, interlocutors may use different forms and contents in the situation which they are involved in. Misunderstanding may occur if non-native speakers fail to perform a refusal in the foreign language because they depend up on their native language strategies, which might be different from those of the foreign language.

Although refusal speech acts are universal across cultures, their occurrence, the situational and social contexts in which they are found, and their linguistic forms are all culture-specific. According to Gass and Selinker (1994), "all languages have a means of performing speech acts and presumably speech acts themselves are universal, yet the form used in specific speech acts varies from culture to culture". The present paper assumes that speech acts reflect the cultural norms and values which are possessed by the speakers of Saudi Arabian and American English. The study attempts to answer the following questions.

(1) how can refusal strategies be described in two different cultures?

(2) what are the contents and the frequencies of these strategies? 
(3) what do these strategies imply about the Saudis and American cultures when performing the speech acts of refusals?

\section{Literature Review}

This section deals with the two concepts of Collectivism and Individualism. Some previous research on the topic is also reviewed here:

\subsection{Collectivism vs Individualism}

Triandis (1995) defines collectivism as a

social pattern consisting of closely linked individuals who see themselves as parts of one or more collectives (family, co-workers, tribe, or nation); are primarily motivated by the norms of, and duties imposed by, those collectives; are willing to give priority to the goals of these collectives over their own personal goals; and emphasize their connectedness to members of these collectives.

Individualism is also defined as a "social pattern that consists of loosely linked individuals who view themselves as independent of collectives; are primarily motivated by their own preferences, needs, rights, and the contracts they have established with others; give priority to their personal goals over the goals of others; and emphasize rational analysis of the advantages and disadvantages of associating with others" (Triandis 1995).

According to Triandis, collectivism is a more common cultural pattern in Asia, Africa, South America, and the Pacific, while individualism is a more common cultural pattern in Western Europe and the US. In individualistic cultures, the self is separate from the group, while in collectivist cultures the self is part of the group. In individualist cultures, people join or leave the group on the basis of costs and benefits of group membership. Individualists start conversation very easily, even with strangers and like to associate with other groups of people. They do not, however, get into intimate relationships, and they tend to form short-term relationships.

In contrast, collectivists are attached to fewer groups, which give them their identity. They are group-dependent, so they hardly ever switch in-groups. Any change of in-group causes major changes in attitudes and behaviors. Collectivists are poor joiners of new groups and perform poorly when they meet people for the first time. Once they get to know the other person, however, the coldness is replaced by more intense interaction. Furthermore, collectivists prefer long-term relationships, and they value in-group harmony. This is why they avoid confrontation. In contrast, individualists do not avoid confrontation, since they prefer clarity of situation over harmony.

Triandis (1988) points out that individuals in collectivistic cultures are seen as representatives of the in-group rather than as persons. Unlike individualistic cultures, the in-groups are "defined through tradition" among collectivist cultures (p. 75) This means that only one or two in-groups usually become dominant in collectivistic cultures (e.g., family and nationality). Triandis, Brislin, and Hui (1988) claim that there are several stable characteristics or qualities by which individualistic and collectivistic cultures can be differentiated. One of these differences is self-reliance, which means the freedom to do whatever one chooses. Another difference is related to competition with others, which characterizes people in individualistic cultures.

In contrast, in collectivistic cultures the group has to take care of its members and compete as a group, rather than as separate individuals, either with in-group or out-group members. Moreover, individual achievement is more emphasized in individualistic cultures than in collectivistic cultures, where achievement is a duty of the whole group and the individual is only a representative of the group.

Hui and Triandis (1986) studied a sample of 49 psychologists and anthropologists from different parts of the world to identify how individualist and collectivist persons act in different situations. Their findings indicated that the main differences between the two were as follows: unlike individualist persons, collectivist persons are viewed as more likely to be subject to their in-group influence, to have more consideration for in-group members' opinions when making major personal decisions, and to have a tendency for sharing material resources. As understood from the above discussion, there is a strong correlation between high authoritarianism of and loyalty to the in-groups, especially the family and collectivism. One might claim that these are true characteristics of the family in Saudi culture. That is, loyalty and duty to the family are greater than other social or business-related responsibilities. This might be attributed to the fact that the status of individuals in Saudi Arabia is derived from their membership of the group family, village, and tribe, and is not usually determined by their individual capacities. Consequently, the entire family feels ashamed and equally responsible when one member is engaged, for example, in a dishonorable act. 


\subsection{Previous Studies of Refusals}

In this section, some previous studies that examined and described speech acts of refusal, or refusal strategies, within different cultures are reviewed. In particular, I will comment briefly on the works by Beebe et al. (1990), Putri (2010), Gungormezler (2016) and Saad et al. (2016).

\subsubsection{Beebe et al. (1990)}

One of the most significant studies on refusal strategies was conducted by Beebe et al. (1990); they investigated the differences and similarities between Japanese speaking Japanese, Japanese speaking English, and American English speakers. Beebe et al. (1990) also took the social status and the social distance between interlocutors into consideration. Their findings about Americans' refusals indicate that Americans usually start with a positive expression, such as "I would like to," followed by regret and then an excuse (Note 1). This study found that Japanese speakers refuse differently, based on the social status of interlocutors, while Americans are more influenced by the degree of familiarity of social distance from the interlocutors. Japanese speakers showed different frequencies of semantic formulas between higher and lower status requesters, while Americans did not. Japanese speakers did not apologize or express regret when they refuse a lower status interlocutor. Americans, on the other hand, pay attention to social distance. Americans offered brief refusals to both higher and lower status and more detailed responses to peers. Japanese speakers also tended to give vague and unspecified excuses, whereas Americans gave specific ones.

Beebe et al. (1990) argued that in the case of refusing a request for buying a toy for a daughter, "Sorry honey, I can't buy it because it is not fit for your age. I'll buy you another one," the formula comprises (regret) + (excuse) + (alternative). According to this system, the direct formulas were either performative (I refuse), non-performative (No), or statements of negative willingness (I can't), as listed above. Performatives are self-naming utterances, in which the performative verb usually refers to the act in which the speaker is involved at the moment of speech (Leech, 1983), for example, (I refuse your suggestion). Non-performative statements can be expressed with "no" as direct refusal, or negative willingness such as using "not" or any other word that semantically negates an utterance, such as "can't". The findings of their study showed that there were significant differences between Japanese and American in the order, frequency, and content of the semantic formulas in refusals (Note 2).

\subsubsection{Putri (2010)}

Putri (2010) investigated refusal strategies in English speech. This study explores different types of refusals, their strategies, and processes. Twenty-three episodes of Ugly Betty Serials (that reflect the real lives of Americans) were selected and the document analysis research technique was employed for data analysis. The study found out that more than one refusal strategy is used by each character of the serial; however, the most frequently used ones are direct refusals, explanations/reason, and adjunct. The conclusions drawn by Putri (2010) are summed up as follows:

1) Requests, offers and invitations are the initiating acts which trigger the act of refusals.

2) In the American society, direct refusals and explanations are the most frequently used strategies. However, in refusing requests of offers, direct refusals are followed by expressions of gratitude.

3) One refusal can include more than one refusal strategy; they are pre-refusals, head acts and post-refusals.

4) The initiators normally accept respondents' refusals; negotiations rarely follow a refusal.

\subsubsection{Gungormezler (2016)}

This study investigated the politeness strategies employed by Turkish learners of English. He compared these strategies to those employed by American English speakers. Participants included 24 candidates who were requested to complete a background survey, an open role-play and a semi-structured interview. Refusal interactions were coded. The study found that excuse/reason/explanation was the preferable strategy of the two groups. The Turkish group proved to be more specific in providing explanations and justifications. The American speakers normally refuse without giving reasons. American speakers use direct strategies more frequently than Turkish students. The study found that the Turkish learners were aware of the differences between them and the Americans regarding their preferred ways of refusal.

2.2.4 Saad, N., Bidin, S. J., and Shdin, A. (2016)

Saad et al. (2016) conducted a comparative and contrastive study on refusal speech acts used by Malay speakers of English and native speakers of English. The types and contents of these strategies as employed by the two groups were examined. Data were collected using "An Enhanced Open Role-play". The study included 21 Malay 
speakers of English and 12 native speakers of English. Data were analyzed qualitatively after being classified into semantic refusal strategies and politeness strategies. This study found that the two groups shared some common similarities regarding the types and contents of the refusal strategies. The situational context of the finding was the refusal of higher status interlocutors' requests. As for native speakers of English, they use direct strategies more frequently, and their use of indirect strategies and adjuncts highlights their Western values; however, they maintain the Eastern values, which are of high importance to the group.

In the literature, several studies have been written about the use of refusal strategies by Arabs. The use of refusal strategies in the Saudi and American cultures has not been compared. However, among the research done on Arabic was that of AL-Issa (1998). He investigated refusal strategies using a written Discourse Completion Task (DCT) made by Jordanian Arab speakers and Americans. His findings showed that Jordanians made use of regret statements (e.g., I'm sorry) more often than their American counterparts. Both groups, however, followed their strategies with reasons and explanations.

\section{Methods}

\subsection{Hypothesis and Methodology of the Study}

This part presents the hypothesis of the study. It describes the design of the DCT, and the methodological steps and procedures in carrying out this task.

Saudis (native speakers of Arabic) and Americans (native speakers of English) are assumed to present different refusal performances because of their different cultures: Saudis' collectivistic culture and Americans' individualistic culture. More specifically, it is expected that:

Unlike Americans, Saudis will make less use of direct refusals and will show more regret in their refusals.

Saudis will make more use of explanations/excuses in their refusals than Americans.

\subsection{Participants and Data Collection}

Twenty students participated in this study - ten Saudis and ten Americans-with an equal number of female students in each group. The participants were from different majors and were not asked to identify themselves. They were told that they were participating in a contrastive socio-cultural study of refusals. Furthermore, they were urged to indicate what they would do in real situations, rather than what they thought they should do.

The study included two phases of data collection and analyses. To elicit data from both the Saudi and American participants, a DCT was designed. In phase one, data was elicited from Saudi participants, using a DCT design. In phase two, data were elicited from American participants using a DCT design. The design of the DCT employed here relies, to a great extent, on previously designed DCTs (e.g., Beebe et al., 1990; Chao-Chih \& Mary, 1996). However, the situations used in the study were modified to meet the purpose of this this study and the nature of the participants, as well as to comply with the cultural norms of the participants.

The DCT consists of eight situations (see appendix A). These situations were used to elicit refusal responses rather than acceptance responses. The directions were written out on the DCT, indicating that refusal is the required/preferred response. Two situations required a refusal to a high-status interlocutor, two to a low-status interlocutor, and four to an interlocutor of equal status. The four situations concerned with an equal status differed in familiarity with the person being refused, i.e., one being a colleague and the other an intimate friend. This might demonstrate a difference in social distances. The purpose of having these different situations was to avoid the restriction that certain situations might have on the responses. The DCT was administered in both languages, Arabic and English.

\section{Data Analysis}

The speech acts of refusals were analyzed as consisting of a sequence of semantic formulas, using Beebe et al. (1990) as the basis of the study. However, slightly different semantic formulas were used in this piece of research in which "explanation" was also considered as "an excuse". The semantic formulas represent the means by which a particular speech act is accomplished in terms of the primary content of an utterance. For example, if a participant refused a request for help by saying, "I am sorry, I am late for an appointment, why don't you ask someone else?" It was analyzed as an expression of regret, explanation, and offer of an alternative (Beebe et al., 1990). In my analysis, it is considered as consisting of "regret", "explanation/excuse", and "alternative". Such expressions are easily comprehended and quietly expressive.

In this paper, the data analysis will be divided into two parts: part one will deal with refusals of invitations, while part two will deal with refusals of requests. Each part consists of four situations, and each situation will be discussed separately (for situations, see appendix A). 


\subsection{Refusal to Invitations}

Table 1. Contents and frequencies of refusal strategies for invitation in different situations

\begin{tabular}{lllllllllll}
\hline Strategies & \multicolumn{2}{l}{ Thanking } & \multicolumn{2}{l}{ Positive/wish } & \multicolumn{2}{l}{ Regret } & \multicolumn{2}{c}{ Explanation } & \multicolumn{2}{c}{ Alternative } \\
\hline Participants & A & AMR & A & AMR & A & AMR & A & AMR & A & AMR \\
\hline Refusing Low Status & 3 & 1 & 0 & 6 & 4 & 3 & 9 & 9 & 3 & 7 \\
Refusing High Status & 4 & 4 & 4 & 3 & 4 & 3 & 9 & 7 & 2 & 1 \\
Refusing Colleague & 3 & 1 & 2 & 1 & 4 & 7 & 7 & 5 & 4 & 3 \\
Refusing an intimate Friend & 3 & 0 & 2 & 1 & 6 & 7 & 7 & 8 & 3 & 1 \\
Total & 13 & 5 & 8 & 11 & 18 & 20 & 32 & 29 & 12 & 12 \\
Percentage & $33 \%$ & $13 \%$ & $20 \%$ & $28 \%$ & $45 \%$ & $50 \%$ & $80 \%$ & $73 \%$ & $30 \%$ & $30 \%$ \\
\hline
\end{tabular}

Note. $\mathrm{A}=$ Arabs; $\mathrm{AMR}=$ Americans.

Table 1 shows that the speech act of refusal of an invitation usually consists of the following (for examples of each category, see appendix B):

1) Thanking: expressing thanking for the invitation.

2) Positive/wish: giving a positive opinion about the invitation and wishing to be able to accept it.

3) Regret: expressing regret about not being able to accept the invitation.

4) Reasons/Excuse (explanation): giving reasons for not being able to accept the invitation.

5) Alternative: suggesting a future time for accepting the invitation.

All the data obtained from the DCT showed that neither Arabs nor Americans employed any direct refusals (e.g., 'No' or 'I refuse'). However, some of the informants used expressions like "I can't come because...." or "I will be unable to come because ...", but I consider them as indirect refusals. Beebe et al. (1990) consider these as direct refusals, putting them under "negative willingness/ability", but I consider them as indirect refusals. This is because the illocutionary force of such semantic formulas does not entail direct refusal, rather I show the inability to accept.

As Table 1 suggests, all the participants from both cultures use these semantic formulas almost in similar order (Note 3) but with different frequencies. That is not to say that they use these five formulas for each situation. Instead, participants always combine at least three of them for most of the situations (e.g., thanking, regret, and explanation; or regret, explanation, and alternative). The results show only a few instances where two formulas are employed, i.e., "regret" and "explanation".

Arabs employed more "thanking" in these situations, except in the second one where the frequency is equal for both groups. This can be attributed to the fact that "thanking" in most Arab cultures is a sign of polite refusal of an invitation and offer, without even saying "no" or giving an explanation or excuse. Since both Arabs and Americans employed the same semantic contents and order, we shall turn our discussion here to the frequencies of using each strategy according to the status of the interlocutor.

\subsubsection{Situation One}

In this situation the participant is asked to refuse a person higher in social status. The results show that Arabs employ "thanking" more frequently (3/1). However, Americans make more use of "positive feeling/opinion" $(6 / 0)$. This might be taken as an indirect way of showing gratitude and appreciation for the invitation, and as a compensation for not using "thanking".

The results also show that the participants from both cultures use "regret" with the same frequency in this situation (9/9). On the other hand, Americans offer more alternatives than Arabs do (7/3). This might suggest that Americans perhaps show their appreciation by implying that they would accept the invitation, even from low-status, if they were free. By suggesting an alternative to they want to show the value they attach to the invitation. Arabs, on the other hand, might show this by using "thanking" as a polite way of refusing and showing appreciation.

\subsubsection{Situation Two}

In refusing the invitation of a high social status person, Arabs and Americans show no significant difference in the frequencies of using refusal strategies. However, when comparing this situation with the previous one, a number of differences can be found in the way these strategies are employed by both Arabs and Americans: 
- Both employ more "thanking". This might be seen as a normal approach when dealing with a high-status interlocutor.

- Arabs use "positive/wish" strategy more than in the first situation (4/0), while Americans use it less (3/6).

- There is a dramatic decrease in the use of "alternative" by Americans (1/6).

4.1.3 Situations Three and Four

Arabs use "thanking" strategy more often than Americans do in both situations. Since the invitation is either from a colleague of an intimate friend, "positive" strategy is used less frequently by both Arabs and Americans. Americans seem to use more "regret" and less "explanation" in these two situations when compared with the previous two. In contrast, Arabs use less "regret" and more "explanation". Furthermore, Arabs use more "alternative" than Americans, especially with an intimate friend. This might indicate that Arabs try to avoid a direct "no", which they consider as an impolite and improper way of refusing even an intimate friend.

\subsection{Refusing Request}

This part of the DCT elicits refusals to requests. In general, there are no significant differences between Arabs and Americans in the use of the refusal strategies in this part. However, if we relate this to the status of the interlocutor, we will find some differences between Arabs and Americans, as well as within each culture, for different situations.

Table 2. Contents and frequencies of refusal strategies for requests in different situations

\begin{tabular}{lllllllll}
\hline Strategies & Direct & \multicolumn{3}{c}{ Regret } & \multicolumn{2}{c}{ Explanation } & \multicolumn{2}{c}{ Alternative } \\
\hline Participants & A & AMR & A & AMR & A & AMR & A & AMR \\
\hline Refusing Low Status & 2 & 2 & 1 & 3 & 6 & 5 & 7 & 3 \\
Refusing High Status & 0 & 0 & 5 & 3 & 9 & 10 & 3 & 0 \\
Refusing a Colleague & 2 & 6 & 7 & 6 & 9 & 7 & 6 & 1 \\
Refusing an intimate Friend & 4 & 1 & 9 & 7 & 8 & 9 & 7 & 0 \\
Total & 8 & 9 & 21 & 19 & 32 & 31 & 23 & 4 \\
Percentage & $20 \%$ & $23 \%$ & $53 \%$ & $48 \%$ & $80 \%$ & $78 \%$ & $58 \%$ & $10 \%$ \\
\hline
\end{tabular}

Table 2 shows that:

- $\quad$ No direct refusal is used when refusing a person with a higher status.

- Americans use more direct refusals with equal status but not with an intimate friend.

- Unlike Americans, Arabs use more direct refusals with an intimate friend.

These differences might be attributed to the respect that both cultures show to the person with a higher status, or it might be due to the social distance between the interlocutors; thus, the refuser uses an indirect refusal strategy. In fact, this assessment is confirmed when considering responses to situations three and four; that is, when there is no social distance, more direct refusals are employed. Americans use direct refusals six times in situation three, while Arabs use it four times in situation four. The differences between Arabs and Americans in the use of direct refusals in situations three and four might imply that social distances between colleagues are greater in the Arab cultures than in the American cultures. Arabs avoid saying "no" in their interactions, even with colleagues, because they consider harmony as the most important element of human relationships. Saying "no" to someone's face is interpreted as an insult to the other person that would cause the breakdown of human relationships.

- $\quad$ Regret is used more frequently with a person of equal status than with a person of higher status. Refusing a request without expressing regret or showing real willingness to comply with the request is considered impolite in both Arab and American cultures (7/6, 9/7).

- Arabs use the "alternative" strategy more often than Americans do in all situations, with different frequencies. High-status interlocutors receive the lowest number of "alternative". Arabs tend to seek the satisfaction and approval of the other person by trying to show their respect, consideration and willingness to comply with the request, if they could, by offering more regrets, wishes and future acceptance.

- None of the Americans use "alternatives" when refusing higher status and an intimate friend. 


\section{Summary and Conclusion}

The findings of this study confirmed our assumption, not in the type of strategies used, but in the frequency of using them. That is, although both groups use similar strategies, they differ in the frequencies of using these strategies, depending on the status of the interlocutor. The results of this study could be summarized as follows:

Both Arabs and Americans employ similar refusal strategies; they use the same semantic formulas in the speech act of refusals.

1) In refusing invitations, the semantic formulas of refusals were analyzed as consisting of the following strategies: "Thanking", "Positive opinion/wish", "Regret", "Explanation", and "Alternative".

2) In refusing a request, the semantic formulas of refusals were analyzed as consisting of the following strategies: "Direct", "Regret", "Explanation", and "Alternative".

3) The semantic formulas of refusal might consist of more than two strategies (e.g., regret, explanation and alternative) in each speech act of refusal.

4) Any combination of strategies is possible from left to right but not vice versa.

Arabs and Americans use these strategies with different frequencies, although not significantly so, depending on the social distance and status of the interlocutor:

1) Both groups use the same strategy with different frequencies in the same situation, e.g., Americans use more "regret" than Arabs do in situation three in part one (7/4).

2) Each group uses the same strategy with different frequencies in different situations, e.g., Americans use more direct refusal with a colleague (6) in situation three in part two than they do with an intimate friend (1), while Arabs do the opposite (2) with a colleague and 4 with an intimate friend).

3) Considering the percentage of the overall use of each strategy for all the situations in each part of the DCT, only the use of two refusal strategies tends to differ significantly between Arabs and Americans. Arabs use "thanking" (33\%) more than Americans (13\%) in part one. They also use "alternative" strategy (58\%) in part two more than Americans (10\%). This can be attributed to the fact that in the Arab culture "thanking" is considered as an indirect and polite way of refusal without saying "no". Furthermore, expressing direct refusal is difficult for an Arab. In fact, this claim might explain why Arabs use more "alternative" strategies in part two. Although they refused the request, they felt that they should give alternatives, which might help satisfy the requester's needs in one way or another. This is a collectivist culture quality.

4) "Regret" and "explanation" strategies were used with high frequencies for all the situations by both groups. In part two, for example, Arabs used "regret" (53\%) and "explanation" (80\%). Americans' use of these strategies was $48 \%$ and $78 \%$, respectively (for more details about percentages of overall use of each strategy, see appendix C).

\section{Research Findings}

Each response was analyzed according to whether it contains any of these four strategies: 'direct', 'regret', 'explanation/excuse', and 'alternative'. As Table 3 indicates, all the participants from both cultures use these strategy formulas in almost similar order but with different frequencies. That is not to say that they use these four formulas for each situation. Instead, participants always combine at least two of them for most of the situations, e.g., regret and explanation, or explanation and alternative. The results reveal only a few instances where three formulas are employed ('regret', 'explanation', and “alternative").

Table 3. The overall use of request refusal strategies in all situations

\begin{tabular}{lllllllll}
\hline & \multicolumn{2}{l}{ Strategies } & \multicolumn{1}{l}{ Explanation/ Excuse } & \multicolumn{2}{l}{ Alternative } \\
\cline { 2 - 8 } & Direct & & Regret & & S & S & A \\
\hline $\mathrm{P}$ & $\mathrm{S}$ & $\mathrm{A}$ & $\mathrm{S}$ & $\mathrm{A}$ & $\mathrm{S}$ & $\mathrm{A}$ & 13 & 15 \\
$\mathrm{~N}$ & 5 & 13 & 35 & 21 & 75 & 64 & 13 & 18 \\
\hline
\end{tabular}

Note. $\mathrm{P}=$ Participants; $\mathrm{S}=$ Saudis; $\mathrm{A}=$ Americans; $\mathrm{N}=$ Number of occurrences.

The request refusal strategies obtained from different situations in this study show that Saudis and Americans use these strategies differently; that is, they use them with different frequencies. It is worth mentioning that the gender variable did not yield any significant differences within each culture. It was found that both genders from 
the same culture use similar strategies with almost the same frequencies. For this reason, the data obtained from female participants from each culture was grouped together and analyzed by considering the overall usage percentages of each strategy.

The overall percentages of using these strategies indicate that Saudis used the 'direct' strategy less frequently than Americans did, but they used 'explanation' and 'regret' strategies more often than Americans. These results confirm the hypotheses of this study. Americans, on the other hand, use more 'alternative' strategies than Saudis, though the difference is not significant $(18 \% / 16 \%)$. The use of 'explanation' ranked first, i.e., 139 occurrences out of 160 possible occurrences: 75 occurrences (94\%) performed by Saudi participants and 64 occurrences (80\%) performed by American participants, followed by "regret': 35 (44\%) occurrences by Saudis and 21 (26\%) by Americans. The use of 'direct' strategy, however, ranked last (5/6\% occurrences by Saudis and 13/16\% by Americans). See Figure 1 below:

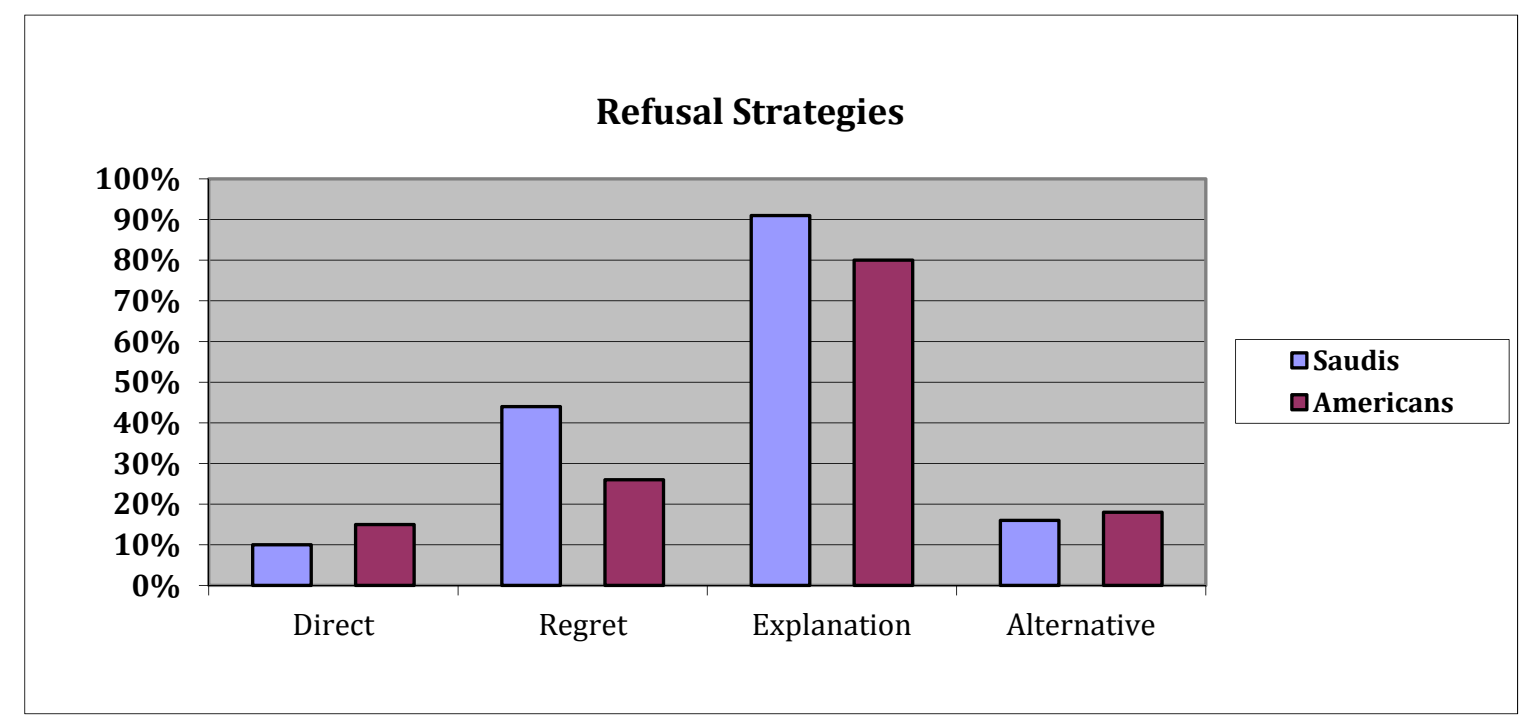

Figure 1. The overall use of request refusal strategies by both groups' refusal strategies Saudis Americans

\section{Discussion}

\section{Direct "no"}

The overall percentage of using this strategy shows that Saudi participants rarely used a direct 'no' in their responses. Only five $(6 \%)$ occurrences of this strategy were found. Americans, on the other hand, employed a direct 'no' a number of times in their responses. This strategy was used thirteen (16\%) times by American participants.

The inclination to avoiding a direct 'no' by Saudis might be attributed to the collectivistic Saudi culture, in which harmony is considered to be the most important element of human relationships. They consider a direct 'no' as an impolite way of refusing that might affect the social relationship between interlocutors. Furthermore, expressing direct refusal is difficult for Saudis. In fact, this was proved when some of the Saudi male participants claimed (Personal Communication) that it was difficult for them to refuse in some of the situations in the DCT. They said they were not used to refusal in such situations. This might explain why Saudis used 'regret' strategy more frequently (44\%/26\%) than the Americans did. Although they refused the request, they felt that they should show regret for being unable to comply with the request. This is a collectivistic culture quality.

\subsection{Explanation/Excuse}

As can be seen from Table 1, Saudis used this strategy more than Americans (94\%/ 80\%). The high percentage of using this strategy by Saudis may be viewed as a way of showing respect, consideration, and willingness to comply with the request. The same might be true for Americans.

In offering an explanation/excuse, Americans in most cases gave specific details in their explanation, e.g., "I am sorry, I have a group study in the library within fifteen minutes," or "I am sorry, but I have a lot of work to finish before the next class," in response to the adviser's request to stay by the phone. Saudis, on the other hand, did not give specific details in most of their explanations/excuses. Common excuses given by Saudis were "Sorry, I 
am busy," or "I am sorry, I have another appointment," in responding to the same situation as above. These differences might be explained in terms of the cultural difference between the two groups. In the Saudi culture people tend to give little information and vague explanations, because they believe that details of their refusals are personal and they need not tell others about it. Another reason might be that they do not want to offer the actual excuse explicitly, because what seems to be a good excuse for the refuser might not be a convincing one for the person involved in the refusal speech event, who may view it as unwillingness to help or do a favor for her/him. This can be interpreted as a way of avoiding confrontation, which is a characteristic of collectivistic cultures. Americans, however, usually gave the necessary information explicitly and in detail. This is similar to Beebe et al.'s findings above.

Furthermore, Americans tended to be more to the point in their excuses/explanations and stating their inclination as reason for their refusal. Saudis tended to be less direct and used explanations other than their own inclinations for refusing. For example, some Saudi participants used family circumstances in their explanations, such as "I have to take my family out," or "I need the car to take my kids to the dentist," if the request was about borrowing a car, while Americans gave explanations expressing their true inclinations, such as "I am sorry, but I am pretty particular about my car," or "I make it a policy not to lend my car to anyone." Again, this kind of explanation/excuse can be attributed to cultural differences. In Saudi collectivistic culture, in-group interest is more important than individual interest, and harmony among group members is of utmost importance. In contrast, American culture is considered be to an individualistic culture in which individual interest is more important than the group interest. Because of these cultural differences, Saudis used uncontrollable excuses (e.g., their family, health). In other words, they used family-related circumstances which they consider to be beyond their control as an excuse.

\subsection{Regret}

The 'regret' strategy was used more by Saudis (44\% in Saudi responses and 26\% in the Americans'). The use of this strategy could reveal statistically significant differences. This might show that Saudis are more concerned about the other interlocutor, wanting to demonstrate their regret for being unable to comply with the desire or request of the other member of their group. Refusing a request without feeling sorry or showing real willingness to comply with the request is considered impolite in Saudi culture. Moreover, by doing this, they try to maintain their composure and save face, as well as allow the other interlocutors to save face. This result contradicts Beebe et al.'s results (1990) but confirms the first hypothesis. Furthermore, it reflects the characteristics of a collectivistic culture. The contradiction might be attributed to the cultural variations that exist even among collectivistic cultures.

\subsection{Alternative}

The results of this study show that Americans and Saudis used this strategy with almost the same frequencies. The percentages of using it were $18 \%$ and $16 \%$, respectively. The slightly higher use of this strategy on the part of the Americans might explain why they used fewer regrets in their responses. The opposite argument might be true for Saudis in the sense that the high percentage of using the 'regret' strategy might explain why they use fewer alternatives.

\section{Conclusion}

The findings of this study confirmed the paper's hypotheses. That is, although both groups use similar strategies, they differ in the frequency of using these strategies. In other words, Saudis used direct 'no' less frequently in their refusals than Americans, but they use 'regret' and 'explanation' strategies in high frequencies. The differences in employing these strategies can be attributed to the cultural differences between Saudis and Americans, and can be viewed as reflections of the characteristics of the Saudis' collectivistic culture and Americans' individualistic culture. Admittedly, this study has a number of limitations. Firstly, the number of participants was small; thus, the results might not be generalizable. Secondly, data was mainly collected using DCT. Naturalistic data is needed to complement the written data. Last but not least, this study uses mainly one variable (social status). Considering other variables such as age and gender might reveal different findings.

\section{References}

AL-Issa, A. (1998). Socio-pragmatic Transfer in the Performance of Refusals by Jordanian EFL learners: Evidence and Motivating Factors. Unpublished Doctoral Dissertation, Indiana University of Pennsylvania, Indiana, PA.

Al-Mansoob, N. T., Patil, K. S., \& Alrefaee, Y. (2019). A Cross-cultural Study of The Speech Act of Compliments in American English and Yemeni Arabic. LANGKAWI Journal, 5(1), 1-12. 
https://doi.org/10.31332/lkw.v5i1.1271

Beebe, L., Takahashi, T., \& Uliss-Weltz, R. (1990). Pragmatic Transfer in ESL Refusals. In R. Scarcell, E. Anderson \& S. Krashen (Eds), On the Development of Communicative Competence in a Second Language (pp. 55-73). Cambridge, MA: Newbury House.

Blum-Kulka, S., \& House, J. (1989). Cross-cultural and Situation Variation in Requesting Behavior. In S. Blum-Kulka, J. House, \& G. Kasper (Eds.), Cross-Cultural Pragmatics: Requests and Apologies (pp. 123145). Norwood, NJ: Ablex Publishing Corporation.

Brown, P., \& Levinson, S. C. (1978). Universals in Language Usage: Politeness Phenomena. In E. N. Goody (Ed.), Questions and Politeness. Cambridge: Cambridge University Press.

Chao-Chih, L., \& Mary, I. (1996). A Contrastive Pragmatic Study on American English and Mandarin Refusal Strategies. In K. Jaszczolt \& K. Turner (Eds), Contrastive Semantic and Pragmatics: Discourse Strategies (Vol 2, pp. 703-727). https://doi.org/10.1016/S0388-0001(96)00043-5

Gass, S., \& Selinker, L. (1994). Second Language Acquisition: An Introductory Course. Hillsdale, NJ: Lawrence Erlbaum.

Gungormezler, I. (2016). An investigation of the refusal speech act of Turkish learners of English. MA thesis, Kansas State University.

Hui, C., \& Triandis, H. (1986). Individualism-Collectivism. A study of Cross-Cultural Researchers. J. Cross-Cultural Psychology, 17, 225-248. https://doi.org/10.1177/0022002186017002006

Olshtain, E. (1989). Apologie Across Languages. In S. Blum-Kulka, J. House \& G. Kasper (Eds.), Cross-Cultural Pragmatics: Requests and Apologies (pp. 155-173). Norwood, NJ: Ablex Publishing Corporation.

Putri, Y. K. (2010). Refusal Strategies in English Speech: A Pragmatic Study. PhD Dissertation, Universitas Padjadjaran.

Saad, N., Bidin, S. J., \& Shdin A. A. (2016). Refusal strategies by Malay ESL students and English native speakers to refuse a request (pp. 253-266). Proceedings of ICECRS. https://doi.org/10.21070/picecrs.v1i1.609

Triandis, H. (1995). Individualism and Collectivism. Oxford: Westview Press.

Triandis, H., Brislin, R., \& Hui C. (1988). Cross-Cultural Training Across the Individualism-Collectivism Divide. International Journal of International Relations, 12, 269-289. https://doi.org/10.1016/0147-1767(88)90019-3

Wolfson, N. (1981). Complements in Cross Cultural Perspective. TESOL Quarterly, 15, 117-124. https://doi.org/10.2307/3586403

Wolfson, N., Marmor, T., \& Jones, S. (1989). Problems in the Comparison of Speech Acts Across Cultures. In S. Blum-Kulka, J. House \& G. Kasper (Eds.), Cross cultural Pragmatics: Requests and Apologies (pp. 174196). Norwood, NJ: Ablex Publishing Corporation.

Yamagashira, H. (2001). Pragmatic Transfer in Japanese ESL Refusals. Retrieved from http://www.kjunshin.ac.jp/juntan/libhome/bulletin/No31/Yamagashira.pdf

\section{Notes}

Note 1. However, Chao-Chih and Mary (1996) found that fewer than $40 \%$ of their American informants apply the above formula.

Note 2. A semantic formula is described as "the means by which a particular speech act is accomplished, in terms of the primary content of an utterance, such as a reason, an explanation, or an alternative" (Bardovi-Harlig \& Hartford, 1991, p. 48).

Note 3. It should be noticed here that in any combination of two or more semantic formulas, they appear in the order shown in the table. It is also noteworthy that these semantic formulas can appear in any combination from left to right but not vice versa. Thus, they were organized in the table in the same order. For example, "positive", "explanation", and "alternative" strategies are a possible combination that can be found in a single refusal. The reverse did not exist in any of the situations 


\section{Appendix A}

\section{Discourse Completion Task (DCT)}

Instructions: Please read the following situations (scenarios) and write your response in the blank after "you say". Please, respond as you would in actual conversations.

\section{Part one: Invitation}

1) You are the president of a printing company. A salesman from a printing machine company invites you to one of the most expensive restaurants in the city. However, you are busy and can't accept his invitation.

You say

2) Your boss invites you and your colleagues for dinner. Unfortunately, you can't accept his/her invitation.

You say.

3) A colleague invites you to dinner. You can’t accept his/her invitation.

You say

4) An intimate friend invites you to dinner, but you can't accept his/her invitation.

You say

\section{Part two: Request}

1) You are the owner of a bookstore. One of your best workers asks for a raise but you don't want to give him/her one.

You say

2) One of your professors asks if you would like to help plan an orientation for new students. However, you are too busy to take on this extra project this semester.

You say

3) A classmate who regularly misses class asks you to borrow your notes. You would really prefer not to lend them.

You say

4) A friend asks to borrow your car. You would really prefer not to lend your car to anyone.

You say

\section{Appendix B}

Examples of Semantic Formulas quoted from the DCT

\section{1) Thanking:}

"Thank you for the invitation"

"Thanks"

"Oh, thank you"

\section{2) Positive/Wish:}

"I would love to ..."

"That is nice of you"

"I wish I could ..."

"Gosh, I wish I could ..."

"I'd really like to ..."

"It is my pleasure ..."

"your invitation is an honor"

3) Regret:

"I am really sorry..."

"I am sorry" 
"I'm terribly sorry"

"Sorry to apologize"

"Oh, sorry"

"Sorry"

\section{4) Explanation/ Excuse:}

"I have other plans"

"I have a big exam to study for"

"I have a previous engagement"

"I have plans that evening"

\section{"I HAVE AN APPOINTMENT AT THAT NIGHT"}

\section{5) Alternative:}

"Maybe sometime next week"

"May we do this some other time"

"If you can't find anybody else, I'll help"

"Let's discuss this when the time arises"

"Can't we make it later"

"let's go and rent a car for you"

"I can give you a ride"

\section{Appendix C}

Table 4. The percentage of the overall use of each strategy in all the situations in part one

\begin{tabular}{lllllllllll}
\hline Strategies & \multicolumn{2}{l}{ Thanking } & \multicolumn{2}{l}{ Positive/wish } & \multicolumn{2}{l}{ Regret } & \multicolumn{2}{c}{ Explanation } & \multicolumn{2}{c}{ Alternative } \\
\hline participants & A & AMR & A & AMR & A & AMR & A & AMR & A & AMR \\
\hline Percentage & $33 \%$ & $13 \%$ & $20 \%$ & $28 \%$ & $45 \%$ & $50 \%$ & $80 \%$ & $73 \%$ & $30 \%$ & $30 \%$ \\
\hline
\end{tabular}

Table 5. The percentage of the overall use of each strategy in all the situations in part two

\begin{tabular}{lllllllll}
\hline Strategies & Direct & \multicolumn{3}{c}{ Regret } & \multicolumn{2}{c}{ Explanation } & \multicolumn{2}{l}{ Alternative } \\
\hline Participants & A & AMR & A & AMR & A & AMR & A & AMR \\
\hline Percentage & $20 \%$ & $23 \%$ & $53 \%$ & $48 \%$ & $80 \%$ & $78 \%$ & $58 \%$ & $10 \%$ \\
\hline
\end{tabular}

\section{Copyrights}

Copyright for this article is retained by the author, with first publication rights granted to the journal.

This is an open-access article distributed under the terms and conditions of the Creative Commons Attribution license (http://creativecommons.org/licenses/by/4.0/). 